\title{
Chapter 7 \\ Managing Environmental Risks and Promoting Sustainability: Conservation of Forest Resources in Madagascar
}

\author{
Bruno Ramamonjisoa
}

\begin{abstract}
From 1990 to 2005 Madagascar implemented a national environmental policy comprising three successive programs. However, after 15 years of implementation, the results were not as initially expected. Forest degradation had continued unabated, resulting in significant environmental problems, such as loss of soil fertility, siltation of rice paddies and water bodies, and further reduction of water supplies in cities. As a result, food availability in rural areas had deteriorated, aggravating the already high levels of poverty. Sustainable forest management had therefore become crucial to sustainable living, yet the problem was how to implement it in the context of increasing poverty. Assuming that the forest could be sustainable only if it contributed to increasing the income of local people, a method of non-extractive valorization of forests was developed and tested. The method incorporated a range of activities that highlighted the ecosystem services of forests, including environmental education, ecotourism, no tillage agriculture, and the development of rural markets for non-wood products. These activities were expected to incentivize the local community to change their behavior and preserve forest and ecosystem services. However, the approach remained highly localized because it attracted immigration from other areas. This case study therefore concluded that sustainable forest management could not be achieved without integrated management at the regional and national levels, as well as on a local scale. Future research will need to focus on understanding migration, on successful spatial management methods, and on identifying alternative economic incentives for stakeholders.
\end{abstract}

Keywords Forest management $\bullet$ Local community $\bullet$ Local scale $\bullet$ Sustainable living

\footnotetext{
B. Ramamonjisoa $(\bowtie)$

Water and Forest Department, School of Agronomy,

University of Antananarivo, Antananarivo, Madagascar

e-mail: bruno.ramamonjisoa@gmail.com
} 


\subsection{Introduction}

Madagascar is the world's fourth largest island, situated in one of the most biodiverse regions on earth. However, large-scale environmental degradation has occurred on the island. From the 1980s onwards, the International Monetary Fund and the World Bank advocated structural adjustment programs for most African countries, and these led to the establishment of environmental programs and the formulation of strategies for poverty reduction (World Bank 2002). Implementation of such programs and strategies has implicitly become a criterion of eligibility for debt reduction programs. Thus, in addition to a structural adjustment program including market liberalization and the privatization of state companies, in 1989 Madagascar adopted a National Environmental Action Plan (NEAP). It was based on a program spread over 15 years with the primary objective of conserving natural resources, and was monitored to ensure sustainable economic development and improved quality of life. Since the implementation of the NEAP and economic policies linked to foreign direct investment, several additional policies and strategies have also been implemented. Yet, despite more than 15 years of environmental programs and nearly USD400 million in financing, Madagascar's problems have never been solved. Indeed, in 1989, policymakers found that the relevant statistical data were inaccurate because of the general lack of tools to precisely assess the situation and the scale of its evolution. To this day Madagascar still has no tools to measure indicators of environmental quality.

Agricultural production remains the dominant economic activity, providing one third of GDP and $80 \%$ of foreign exchange earnings. However, because of slash and burn practices, persistent fires, and the resulting reduction in forest cover to protect the vast watershed of Madagascar, erosion is still present in almost all areas. This leads to lower soil fertility, increased costs associated with water and road infrastructure, and damage to marine ecosystems. Sustainable management of natural resources is therefore essential to avoid adverse environmental consequences, including loss of species, landslides, drying up of springs, and silting up of lowlands. Forests play a crucial role in stabilizing the agricultural system as well as the soil, and make an important contribution to reducing environmental risk.

Despite the implementation of an environmental program in 1990 and a forest policy in 1997, the forests have continuously deteriorated. They are subject to the combined effects of skimming, which removes many of the species of commercial interest, and slash and burn, which completes the extraction of woody vegetation considered to be of no commercial value (Fig. 7.1). These two causes of forest degradation have never been eradicated because no reform has ever directly addressed the two practices in question. There were proposals to introduce the concept of KoloAla (sustainable production forests) to convert the logging industry's mode of operation to a tender model (based on inventories of existing timber volume on forestry plots). However, no significant changes have been made so far. Meanwhile, the same slash and burn practices continue on the basis of a government ordinance dating back to 1960 (Ramamonjisoa 2004). 


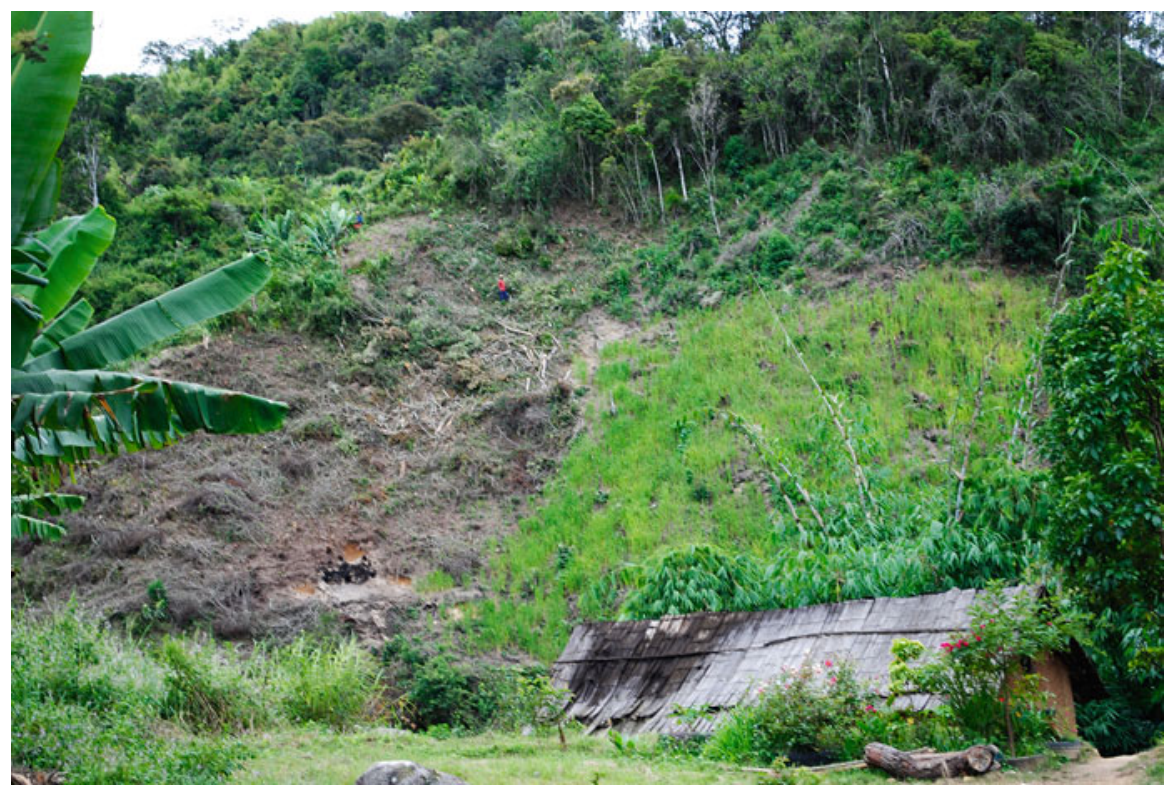

Fig. 7.1 Slash and burn in Madagascar's eastern region

There is now better understanding of the reasons why forest resources continued to deteriorate despite the implementation of the NEAP and its USD400 million funding. Sustainable forest management has become key to sustainable living, yet the problem remains how to implement it in the context of increasing poverty. It is assumed that the forest can be sustainable only if it contributes to increasing the income of local people.

\subsection{Theoretical Explanation}

A sustainable forest management system will be successful only if the community is involved in all activities. Community-based forest management is a promising strategy for achieving this aim that has been applied in Africa over the past two decades. It has the potential to enable mitigation of forest resource degradation throughout the South, and particularly in Africa.

Community-based management will flourish only if it has a sustainable financing system that can redistribute profits to all stakeholders. Based on this assumption, data coming from Madagascan experiences between 2006 and 2010 were used to simulate how business as usual could be changed into standardized forest use (Ramamonjisoa 2010, 2012). The results of this simulation showed that strengthening community management by reorganizing forest use and redistributing its 
benefits was beneficial both for the forest users themselves (i.e., loggers and households) and for the local area (leading to construction of public infrastructure, for example). It also conferred decision-making power at the local level (Bertrand and Montagne 2008; Ramamonjisoa 2010a, b). The only way to compensate for loss of income from slash and burn, fuel wood production, and other extractive activities, therefore, is to improve methods for non-extractive forest valorization that benefit the local population. Such activities have to be distributed equally among households.

\subsection{Case Study}

\subsubsection{Context}

From 1990 to 2005 Madagascar implemented a national environmental policy comprising three successive programs. After 15 years of implementation the results were not as initially expected, and forest degradation had continued unabated. Natural forest cover (not including secondary forests) was 10.7 million ha in 1990 (18.1\% of the national territory), 9.7 million ha in 2000 (16.5\%), and 9.2 million ha in 2005 (15.7 \%) (Ministry of Environment and Forest 2007). The forest degradation had also resulted in significant environmental problems, such as loss of soil fertility, siltation of rice paddies and water bodies (Fig. 7.2), and further reduction

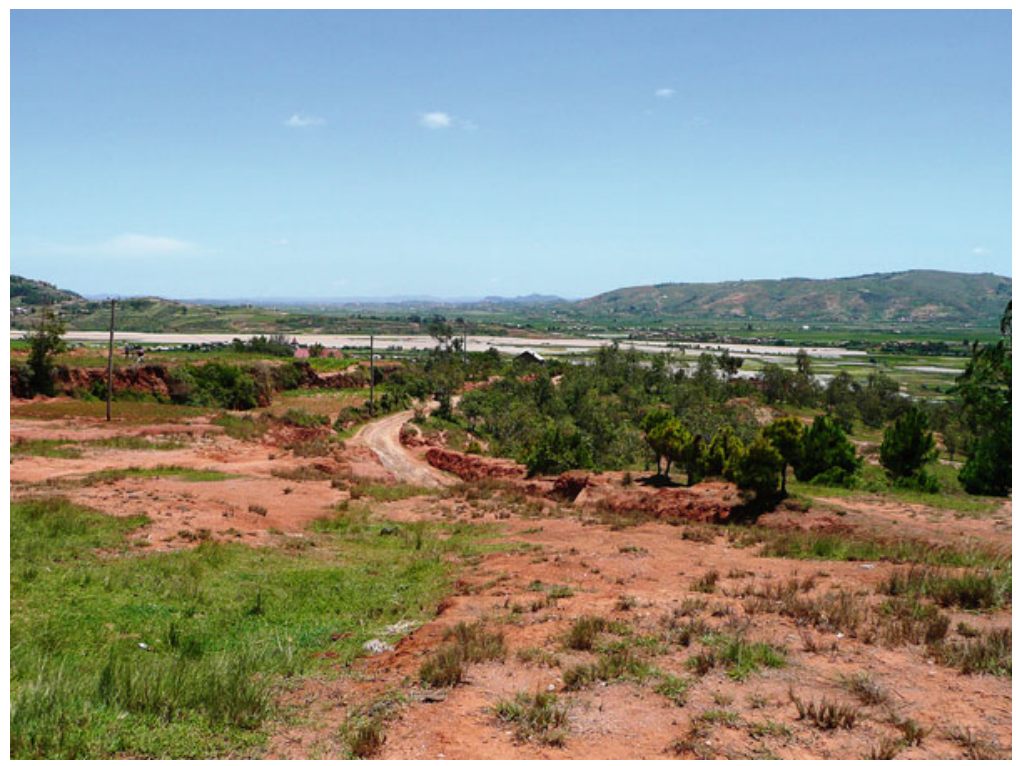

Fig. 7.2 Flooding of rice fields in Madagascar's central region 


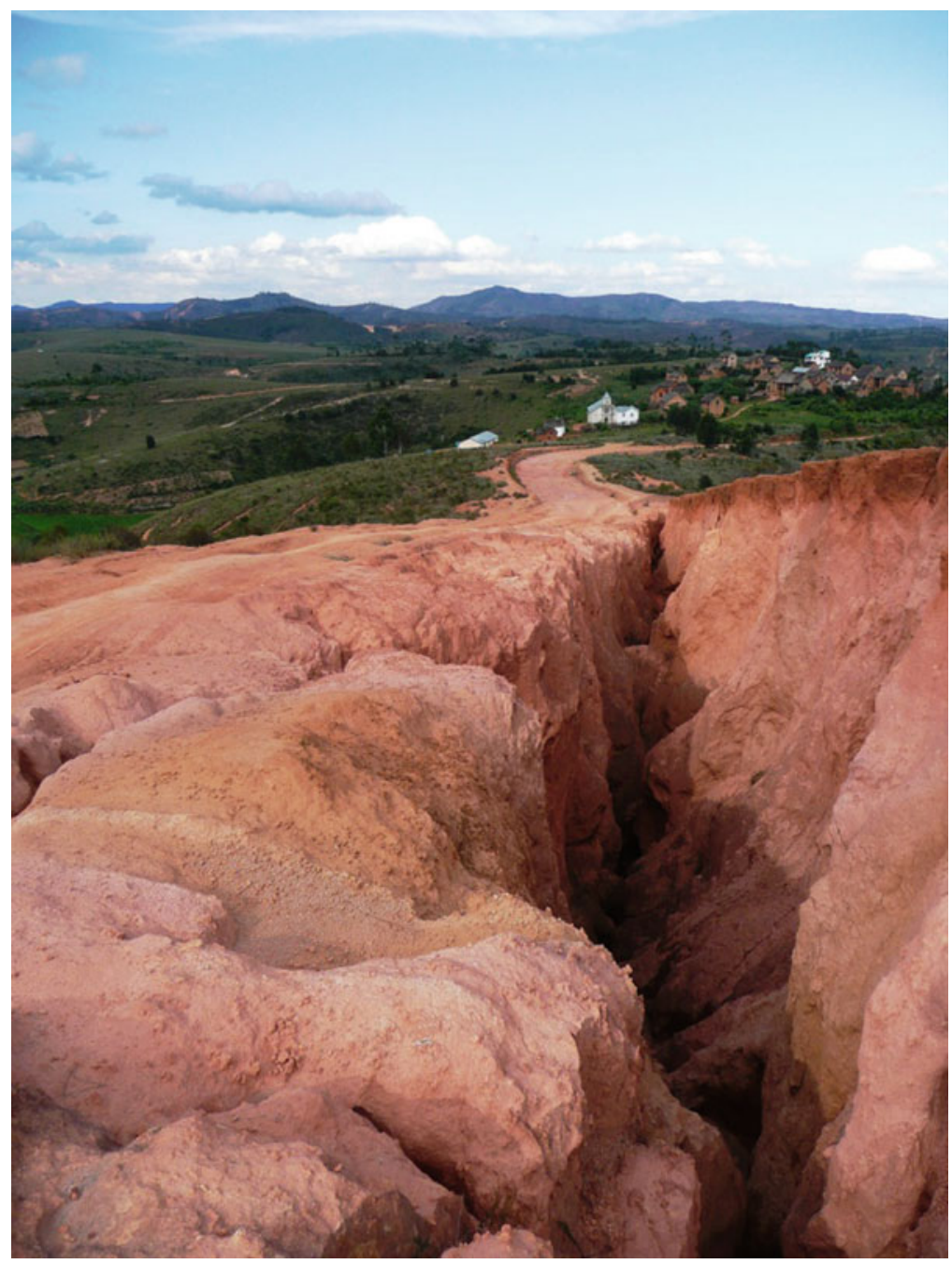

Fig. 7.3 Soil erosion and road degradation in Anjozorobe (north east of Antananarivo)

of water supplies in cities. As a result, food availability in rural areas had deteriorated, aggravating the already high levels of poverty. Sustainable forest management had therefore become crucial to sustainable living.

The poor who have to fund their daily subsistence tend to exploit their natural resources - forests, fisheries, and mines. Land that is ecologically fragile and unsuitable for agriculture is subjected to intensive farming and overgrazing. This causes soil erosion (Fig. 7.3), depletion of water resources, lower yields for crops, and desertification. Women and children in poor households often spend several hours a day fetching water and firewood-time and energy that would be better spent on schooling, 
Table 7.1 Formal and informal governance

\begin{tabular}{lll}
\hline & Formal governance & Informal governance \\
\hline $\begin{array}{l}\text { Annual funds } \\
\text { generated }\end{array}$ & USD20 million & USD73 million \\
Actors & State & State \\
& Donors & Forest service (departments) \\
& Technical partners & Primary banks \\
& International NGOs & Shipping companies \\
& National NGOs & Traders (collectors-intermediates-importers- \\
& Civil societies & exporters, etc.) \\
& Engineering offices & Customs services \\
& Decentralized services & Decentralized communities (fokontany, ${ }^{\text {a }}$ \\
& (including forestry) & municipalities, regions, etc.) \\
& Communities (farmers) & Communities (labor collection and/or sampling) \\
\hline
\end{tabular}

${ }^{a}$ The smallest subdivision of local government

community development, and building good family relations. Land degradation and poverty in rural areas encourage mass migration to already crowded cities, where the lack of clean water, sanitation networks, and garbage collection services contribute to water pollution and disease. Poverty, being associated with high rates of infant mortality, motivates households to have additional children to ensure that more potential breadwinners will survive.

\subsubsection{Poor Governance and Inequality in Income Distribution}

An analysis of Madagascan forest governance highlighted the competition between:

- Formal governance (imposed by donors and conservation NGOs), focused on protection and conservation by means of protected areas, and

- Informal governance (dominated by private operators), based on the exploitation of mining and non-wood forest products (Ramamonjisoa 2005)

The state expects to receive an annual income of nearly USD28 million, which prompted it to divide the entire national territory, including protected areas, into mining squares. This caused juxtaposition of natural resource use (use of the same resource for different economic activities).

Meanwhile, the trade in forest products has still not stopped. In fact, it has actually increased in volume, making environmental management policies focused on conservation even more difficult to implement. The trade in wildlife species has been estimated at a minimum of USD500,000 per year, while the turnover of wood products amounts to around USD73 million per year.

As ever, the degradation of forest resources remains due to the fact that the two types of governance (formal and informal) are both based on monetary incentives 
(Table 7.1). Formal governance cannot replace informal governance because the funds received through formal governance represent only one-quarter of the revenue from illicit practices. In addition, the funds are not well distributed among the actors involved.

The system of conditionality imposed by the structural adjustment programs and misinterpretation of the term "foreign direct investment" have helped to establish priorities that are not necessarily based on the economic viability of natural resources. In addition, the establishment of many non-state institutional structures has helped to generate an antagonism between the administration and conservation NGOs.

Degradation is also explained by the existence of gaps and inconsistencies in legal norms, contributing to shortcomings in management system implementation. In the absence of a forest control system (due to lack of means) these gaps tend to generate and sustain informal norms that are based not on the effect of coercive laws, but on the monetary incentives generated by the marketing of products obtained illicitly.

The juxtaposition of resource use also creates a conflict in the application of legal norms, as well as an inefficient system of coercion of users by the state (Ramamonjisoa 2004). By prescribing two distinct uses for the same land, the state creates inefficiencies in the management system, as in the case of mining squares in protected areas (Fig. 7.4). As a result, procedures are no longer effective and the actors have to negotiate for the administrative services required, such as logging permits and transportation authorization. The service providers therefore become the players who make the decisions, but the factors informing such decisions are economic and social, rather than technical. Consequently, the administration becomes easily corruptible. ${ }^{1}$ In addition, institutional inconsistencies prevent administrators from managing natural resources effectively, while decentralized services become permeable to the intrusion of related issues and purely political. The final explanatory factor in poor governance, moreover, is the behavior of citizens, who tend to regard the necessary procedural documents as products for sale. Almost all such documents, including business licenses, office notices, and instructions, have become commodities. Forest agents say that their equipment and budgets are insufficient, and the lack of performance-based pay demotivates them from working for the public interest, driving them to consider themselves as at the service of particular interests.

\footnotetext{
${ }^{1}$ The determinants of corruption in the forestry sector are many and varied: (1) the remoteness and isolation of forest workers, (2) inadequate checks and sanctions for several years, (3) insufficient work resulting in dependent agents becoming operators, (4) hierarchical political pressure exerted through a network of complicity leading to malfunctions in the procedures and records, and (5) complexity and lack of clarity of records, combined with inadequate updating.

Significant financial and human behavior-related determinants have also been noted, including:

- Inadequate remuneration for officials and the scarcity or absence of compensation in case of displacement;

- Financial avidity among operators;

- Lack of ethics and practice models.
}

(JURECO Studies and Consulting 2009) 


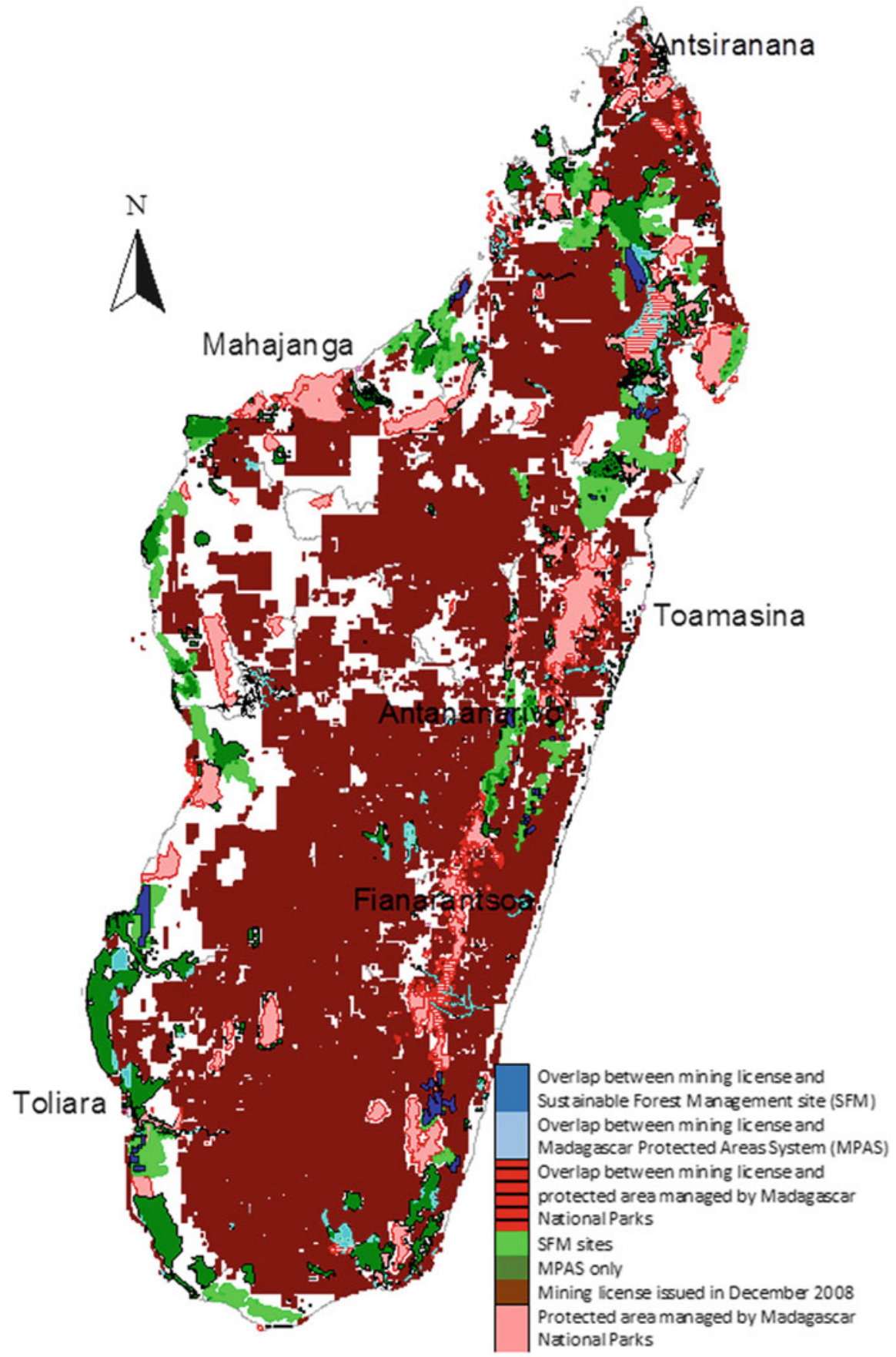

Fig. 7.4 Overlap between protected areas and mining permits (Soanirinavalona 2008) 
Table 7.2 Sources of power and associated rationales

\begin{tabular}{|c|c|c|}
\hline Rationale & Economic & Social \\
\hline $\begin{array}{r}\text { Source of } \\
\text { power }\end{array}$ & $\begin{array}{l}\text { - Possession of a skill or a functional } \\
\text { specialization difficult to replace (the } \\
\text { expert is the only one to have the } \\
\text { know-how, knowledge and experience) } \\
-\quad \text { Control of relations with the } \\
\text { environment } \\
-\quad \text { Communication }\end{array}$ & $\begin{array}{l}\text { Social position based on: } \\
-\quad \text { Prestige (external experience/money) } \\
-\quad \text { Nobility (inheritance) } \\
-\quad \text { Anteriority (age) }\end{array}$ \\
\hline $\begin{array}{l}\text { Type of } \\
\text { power }\end{array}$ & $\begin{array}{l}\text { Authoritative: characterized by a form of } \\
\text { power requiring obedience accepted } \\
\text { without coercion, as well as trust and } \\
\text { respect }\end{array}$ & $\begin{array}{l}\text { Compassionate: a mixture of persuasion } \\
\text { and manipulation that seeks to evoke } \\
\text { emotion, and to compel someone to } \\
\text { do what he did not really want to do }\end{array}$ \\
\hline
\end{tabular}

Source: Ramamonjisoa 2005

Two solutions were proposed to solve the problem: the establishment of a redistributive tax, and capacity building. The proposed introduction of a redistributive tax was based on the principle of focusing action on how we can better capitalize on the existing informal organization, rather than trying to change it. Redistributive taxation should be a tool that works both as an incentive (for state actors in general) and as a means of enforcement (for other players who do not follow the new norms to be established). However, the big issue with this new means of paying for environmental services is the fact that introducing the tax would require the establishment of a new independent organization to manage forest resources. On the other hand, the formulation and implementation of redistributive taxation is expected to solve the budget problems of decentralized and deconcentrated state services (including the forest service, the customs service, decentralized authorities, and municipalities). The forest service, for instance, could make more than twice its entire annual budget by taking $10 \%$ of the total income (amounting to approximately USD73 million per year) from the illegal trade of timber products.

Meanwhile, capacity building is another prerequisite for changing behavior by means of public policies in the short and medium term. In addition, education over the long term can enable the switch to a non-hierarchical coordination system supporting the implementation of sustainable governance to maintain effective forest management.

The inability of formal governance to replace informal governance reflects failures in the development and implementation of public policies. These failures are in fact explained as follows: Sources of power (Table 7.2) within societies are usually based on the possession of a skill or a functional specialization that is difficult to replace, as well as control of environmental relations and communication (Crozier and Friedberg 1996). In Madagascan society, however, power is conferred by prestige, nobility (based on inheritance), and social position based on anteriority (age) in a dominant-dominated hierarchy that is accepted by all and determines access to and use of Madagascar's natural resources (Ramamonjisoa 2005).

The evidence indicates that informal governance has led to a number of norms based on a dominant-dominated hierarchical coordination system. Ever since the 
initial implementation of structural adjustment, this has resulted in prestige (based on external experience/possession of money) replacing competence as the criterion when choosing agents to take charge of natural resource management. Within this context, the actors developed strategies to capture funds at many levels. However, networks are better at capturing funds (because they have a greater redistributive capacity), and it is therefore critical that all stakeholders act in terms of institutional strengthening focused on organization and standards.

The implementation of redistributive taxation was expected not only to help establish a management system adapted to the constraints. In addition, it was expected to generate significant financial resources that could contribute to regional and even national development. No doubt the system would improve the availability of cash at the local and regional levels. In practice, however, trials conducted in the north west of Madagascar (the GESFORCOM Project ${ }^{2}$ ) met with only qualified success.

Community management of forests cannot withstand transactions of external origin that do not lead to local financial autonomy: In Madagascar the USD1.25 million injected for the implementation of $\mathrm{GELOSE}^{3}$ (between 1994 and 2004) neither increased the income of communities, nor contributed to financial volume in the local zones where management transfers were negotiated and contracts signed (Ramamonjisoa and Rabemananjara 2012). In this case, the emergence of local elites overlooking the community undermined efforts. In fact, decentralization provides numerous examples of how village councils can serve to strengthen the local elite, rather than providing a community voice. During transfers of forest management, stakeholders reinterpret "negotiated" standards, taking advantage of the relevant laws. Therefore, despite the transfer, the public administration may continue to play a role in legalizing forest degradation practices, albeit implicitly, and taking premiums from those practices for which the legal basis of the transfer system is unknown or incomprehensible.

Standardized forest use without economic incentives cannot succeed if it is not applied throughout the country or the region. The viability of the system depends on illicit practices ceasing to exist. Moreover, if the share of benefits offered by the new system remains insignificant, illegal logging will not be prevented. The conclusion, therefore, is that projects must not be isolated, but should be rolled out across the country or region to stop the existing leakage of funds. This would require a new forest policy, a new action plan, and, above all, control of the forests.

In summary, poor governance and inequality in distribution of income have become key issues because of stakeholder behavior and the ever-increasing forest degradation it induces.

\footnotetext{
${ }^{2}$ Community and municipality forest management (Gestion forestière communale et communautaire) was a project funded by the European Union between 2007 and 2010 in three countries (Madagascar, Mali, and Niger). The goal of the project was to comparatively test improved forest management methods in the three countries. Activities were focused on the development of forest management plans, the reinforcement of control systems, and the development of new taxation systems, the proceeds of which were shared among the main managers of forest resources, such as the forest service, the local community, and the municipality. See http://www.gesforcom.eu

${ }^{3}$ Gestion locale sécurisée (secured local management)
} 


\subsubsection{More Income, Less Logging}

Development of a range of activities that highlight the ecosystem services of forests - including environmental education, ecotourism, no tillage agriculture, and the development of rural markets for non-wood products - is the only alternative solution to address all the constraints, including poor governance, inequality in the distribution of income, and poverty. Tested in the national park of Ranomafana and elsewhere, this method demonstrated that income flows into rural areas directly as a result of certain activities such as environmental education, ecotourism, and the development of rural markets for non-wood products.

Entrance fees for these parks represented only $30 \%$ of a tourist's total travel expenses, while the other $70 \%$ were indirect expenses paid directly to local stakeholders (in return for accommodation, food, or handicrafts) (Ramamonjisoa 2000). The increased income for local communities resulted in a $0.07 \%$ decrease in forest degradation in these areas (Ministry of Environment and Forest 2007).

A trial is being conducted in the Mandraka station to try to overcome the gaps in the case study above. The Mandraka station is one of the four forest training stations of the School of Agronomy's Water and Forest Department, situated $70 \mathrm{~km}$ east of Antananarivo. The site includes fragments of rainy natural forests and areas reforested using native species. Ecotourism incorporating an environmental education system was set up within the local community, as well as a no tillage agriculture system and a rural market for non-wood forest products. Local communities needed to be involved soon after the activities were launched to ensure the success of the projects (Figs. 7.5 and 7.6).

\subsection{Key Issues and Recommendations}

Unfortunately, the trial described above is not certain to halt forest degradation because it induces additional constraints such as migration from the poorest regions in the south to these areas, while it does not successfully inhibit slash and burn practices. By general consensus, direct degradation is attributable to the spread of slash and burn for rice or maize cultivation, taking place even inside protected areas. ${ }^{4}$ Both migration and slash and burn are regarded as key drivers of deforestation and will be tackled to ensure that a sustainable management system can be implemented. A system of no tillage agriculture could replace slash and burn practices,

\footnotetext{
${ }^{4}$ A study conducted in 2011 focused on assessing the current threats and biological impact caused by traffic of precious woods and hunting of lemurs, concluding that: (1) deforestation accelerated at a rate of $0.36 \%$ per annum between 2005 and 2010 in the Masoala National Park, and $0.71 \%$ per annum in the Marojejy National Park, and (2) analysis of satellite photos clearly showed some glades that always appeared at the edges of the forests. This was not a result of selective logging, but rather of slash and burn activities and other land uses. Glades were almost always connected to the hydrographic network, and were particularly remarkable for the river Ampanio in the Masoala park (LRA 2011).
} 


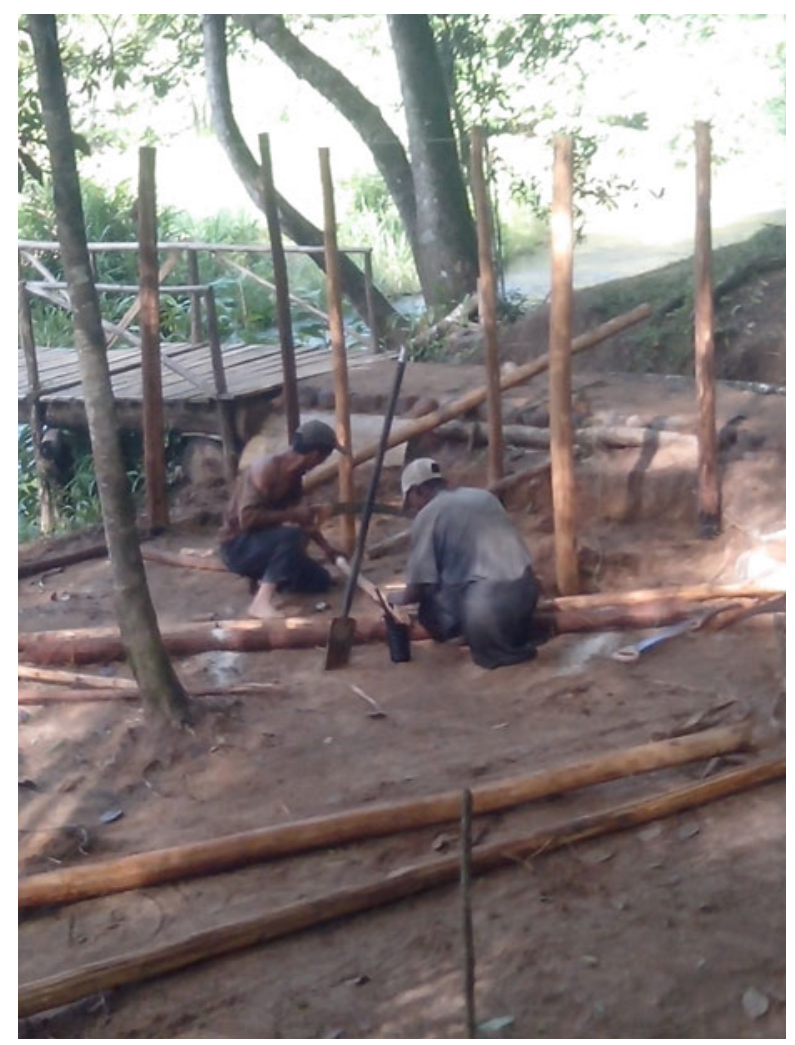

Fig. 7.5 Community working-Men in action

while setting up a rural market for non-wood products could prevent forest logging. The strategy is to avoid implementing only one conservation-related activity, but to combine two or three depending on the magnitude of forest degradation. These solutions could be instituted in different regions-including migration departure points, as well as final destinations - and on various scales, and should be regarded as integrated management schemes on a national, regional, or local level.

Some key questions remain to be addressed in the future: How can slash and burn practices be effectively replaced considering the socioeconomic, cultural, and technical aspects of this degradation-inducing agricultural system? Can we expect these practices to be replaced, as the great majority of them are illegal? How can rural markets for nonwood products that really benefit local farmers be established? In addition, research needs to focus on understanding migration, on successful spatial management methods, and on identifying alternative economic incentives for stakeholders.

Full comprehension of these phenomena could help in establishing realistic strategies to minimize environmental risk and promote sustainability. This is the only way to fight scarcity and thus break the vicious cycle of poverty and deforestation. 


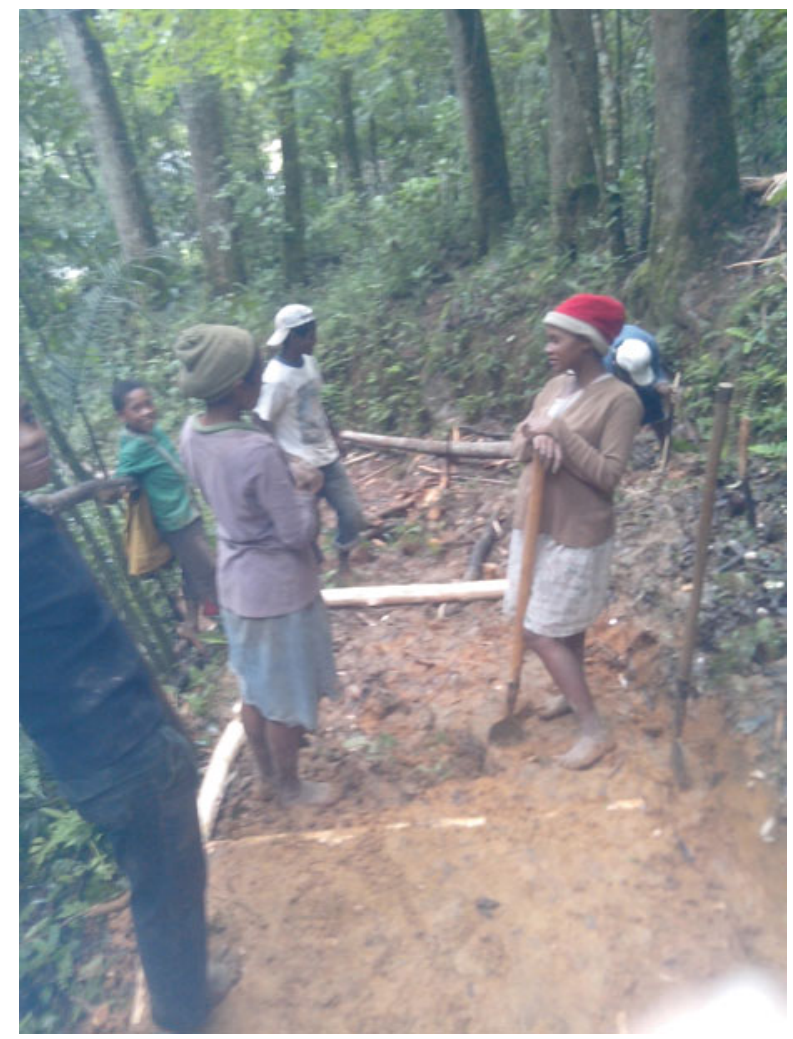

Fig. 7.6 Community in action-A gender-based approach

Open Access This article is distributed under the terms of the Creative Commons Attribution Noncommercial License which permits any noncommercial use, distribution, and reproduction in any medium, provided the original author(s) and source are credited.

\section{References}

Bertrand A, Montagne P (2008) Domanialité, fiscalité et contrôle : la gouvernance locale contractuelle des ressources renouvelables dans un contexte de décentralisation (Niger, Mali et Madagascar). Mondes en développement 141:11-28. doi:10.3917/med.141.0011

Crozier M, Friedberg E (1996) Organization theory. Centre for the Sociology of Organizations, Paris, p 86

JURECO Studies and Consulting (2009) The situation of corruption in the environment \& forestry. JURECO Studies and Consulting, Antananarivo, p 77

Laboratoire de Recherche Appliquée (LRA), ESSA-forêts (May 2011) Réalisation d'état des lieux des valeurs universelles exceptionnelles dans les secteurs perturbés des parcs Masoala et Marojejy (capitalisation des acquis), Rapport préliminaire, p 36 
Ministry of Environment and Forest (2007) General direction of forest: forest degradation analysis. Conservation International, Antananarivo, p 102

Ramamonjisoa BS (2000) Socio economic context of forest conservation in Madagascar. Conservation International, Antananarivo, p 59

Ramamonjisoa BS (2004) Origin and impact of national policies for natural resource management: the case of Madagascar. J Forestier Suisse 2004:467-475

Ramamonjisoa BS (2005) La reconstruction du système de régulation de l'usage des ressources forestières à Madagascar : la nécessite d'une éducation économique. Mémoire d'Habilitation à Diriger des Recherches. Water and Forest Department, School of Agronomy, University of Antananarivo, p 260

Ramamonjisoa BS (2010) Rapport thématique économie et gestion des filières. Projet GESFORCOM, November 2010, p 52

Ramamonjisoa BS (2012) Governance and political nature in Madagascar Geopolitics and environment the lessons of the Malagasy experience. IRD Collection Objectif Sud, Montpellier, pp 187-206

Ramamonjisoa BS, Rabemananjara Z (2012) Une évaluation économique de la foresterie communautaire. Dans Enjeux et moyens d'une foresterie paysanne contractualisée. Expériences de système de gestion locale à Madagascar. Presse universitaire de Bordeaux Les Cahiers d'Outre-Mer 65(257):125-155

Soanirinavalona RO (2008) Contribution à la résolution des problèmes de cohabitation entre création d'aires protégées et activités minières. Mémoire de DEA en Sciences agronomiques. Département des Eaux et Forets. ESSAgronomiques. Université d'Antananarivo, p 115

World Bank (2002) Annual report 2002, Volume 1, Year in Review, Antananarivo, p 171 